\title{
Management of choroid plexus tumors-an institutional experience
}

\author{
Arthur Hosmann $^{1,2} \cdot$ Felix Hinker $^{1} \cdot$ Christian Dorfer $^{1,2} \cdot$ Irene Slavc $^{3,2} \cdot$ Christine Haberler $^{4,2} \cdot$ Karin Dieckmann $^{5,2}$. \\ Engelbert Knosp ${ }^{1,2} \cdot$ Thomas Czech ${ }^{1,2}$
}

Received: 8 November 2018 / Accepted: 31 January 2019 / Published online: 19 February 2019

(C) The Author(s) 2019

\begin{abstract}
Background Choroid plexus tumors are rare entities. Resection is the mainstay of treatment in grade I and grade II tumors and adjuvant treatment is usually reserved for the less frequent choroid plexus carcinoma (CPC). Outcome is not only related to their histological grade but also dependent on their size, location, and presence of often multifactorial disturbances of cerebrospinal fluid (CSF) circulation.

Methods Retrospective analysis of 36 consecutive patients operated on a choroid plexus tumor at our institution in a mixed pediatric and adult population between 1991 and 2016.

Results Twenty-one CPP, 11 atypical choroid plexus papillomas (aCPP), and four CPC were encountered in 17 children and 19 adults. Regardless of histological grading, gross-total resection (GTR) could be achieved in $91.7 \%$ of patients. Tumor recurrence $(25.0 \%)$ was significantly associated with histological grading $(p=0.004)$, subtotal resection $(p=0.002)$, and intraoperatively evident zones of tumor infiltration $(p=0.001)$. Adjuvant therapy was performed in $19.4 \%$ of patients, mainly diagnosed with CPC. The 5-year overall survival rate was $95.2 \%$ for CPP and $100.0 \%$ for both aCPP and CPC. Survival was related to the extent of resection $(p=0.001)$, tumor progression $(p=0.04)$, and the presence of leptomeningeal metastases $(p=0.002)$. Even after resection, either ventricular or subdural shunting was required in $25.0 \%$ of patients.

Conclusions We could confirm that GTR is crucial for treatment of choroid plexus tumors. Parenchymal tumor infiltration as detected intraoperatively was associated with the extent of resection and not limited to CPC. CSF disturbances mandating treatment may persist after resection.
\end{abstract}

Keywords Atypical choroid plexus papilloma Choroid plexus carcinoma Choroid plexus papilloma $\cdot$ Choroid plexus tumor . Gross-total resection · Infiltration

\section{Abbreviations \\ aCPP Atypical choroid plexus papilloma \\ CSF Cerebrospinal fluid}

This article is part of the Topical Collection on Brain Tumors

Thomas Czech

thomas.czech@meduniwien.ac.at

1 Department of Neurosurgery, Medical University of Vienna, Waehringer Guertel 18-20, 1090 Vienna, Austria

2 Comprehensive Cancer Center-Central Nervous System Tumors Unit (CCC-CNS), Medical University of Vienna, Vienna, Austria

3 Department of Pediatrics and Adolescence Medicine, Medical University of Vienna, Vienna, Austria

4 Institute of Neurology, Medical University of Vienna, Vienna, Austria

5 Department of Radiotherapy, Medical University of Vienna, Vienna, Austria

$\begin{array}{ll}\text { CT } & \text { Computed tomography } \\ \text { CPA } & \text { Cerebellopontine angle } \\ \text { CPC } & \text { Choroid plexus carcinoma } \\ \text { CPP } & \text { Choroid plexus papilloma } \\ \text { CPT } & \text { Choroid plexus tumor } \\ \text { GTR } & \text { Gross-total resection } \\ \text { MRI } & \text { Magnetic resonance imaging } \\ \text { OS } & \text { Overall survival } \\ \text { PFS } & \text { Progression-free survival } \\ \text { STR } & \text { Subtotal resection } \\ \text { WHO } & \text { World Health Organization }\end{array}$

\section{Introduction}

Tumors of the choroid plexus epithelium are rare intraventricular lesions and account for $0.5 \%$ of brain tumors in both children and adults. In children, 10 to $20 \%$ are diagnosed within the first year of life $[9,20,47,49]$ and are usually 
located supratentorially. In adults choroid plexus tumors (CPT) are almost exclusively located infratentorially, representing a reverse situation compared to other tumor entities $[15,17,47]$.

The World Health Organization (WHO) classification differentiates between benign choroid plexus papillomas (CPP; WHO I), aggressive malignant choroid plexus carcinomas (CPC; WHO III), and atypical choroid plexus papillomas (aCPP; WHO II) as an intermediate form. CPC occur mostly in very young children, are typically aggressive, and disseminated at diagnosis in more than $20 \%$ of cases [49].

Although CPTs occur in both children and adults, most case series focus exclusively on an either pediatric or adult population $[7,15,17,22,24,25,30,34,35,39,50]$. However, adequate treatment requires age-specific consideration for optimized outcome. Most patients with CPT can be cured by total resection alone, but perioperative morbidity due to the young age, the intraventricular location, and high tumor vascularization can also negatively affect patients' outcome independent of histological grading [7, 13, 30, 42, 48]. Especially, the high rate of temporary CSF drainage and permanent shunting may contribute to an increased tumorindependent morbidity in these patients [22, 25, 30, 35].

Therefore, we present our 25-year experience in the surgical and postoperative management of CPT in a mixed pediatric and adult patient population. We put a particular focus on age-related tumor characteristics and on surgical considerations specifically with regard to cerebrospinal fluid disturbances, which are usually neglected in existing literature.

\section{Methods}

\section{Patient selection}

All consecutive patients operated on a histologically proven CPT at the Neurosurgical Department of the Medical University Vienna between 1991 and 2016 were included. All tissue samples were reviewed by the university's neuropathology department and re-classified according to the WHO criteria 2016 for CPT. The study protocol was approved by the local ethics committee (EK 2005/2015).

\section{Patient characteristics}

Details for individual cases are shown in Table 1.

Thirty-six consecutive patients were identified, including 17 children (median, 1.2 years; range, $0.2-10.2$ years) and 19 adults (median, 48.5 years; range, 22.7-70.9 years). Sex distribution was nearly equal in children (male:female $=8: 9$ ). For adults, $68.4 \%$ of patients were female. In total, $21 \mathrm{CPP}, 11$ $\mathrm{aCPP}$, and $4 \mathrm{CPC}$ were present in our cohort.
Clinical symptoms at presentation are shown in Table 2, tumor localization and the surgical approach in Table 3. The median tumor size was $3.5 \mathrm{~cm}$ (range, $1.1-10 \mathrm{~cm}$ ).

Dissemination as evidenced by MRI at diagnosis was present in two children with CPC, who presented both with spinal metastases.

\section{Clinical evaluation}

In a retrospective chart review, patient demographics, tumor location, and postoperative characteristics were analyzed. Resection was categorized as either gross-total resection (GTR) or subtotal resection (STR) if residual tumor (< $10 \%$ ) was found on postoperative contrast-enhanced MRI scans. Operative reports were reviewed for surgical details, focusing on evidence for tissue infiltration. Data for intraoperative blood transfusion management was based on anesthesiologic protocols. The decision for adjuvant chemotherapy and/or radiation was made on a case by case basis. Tumor progression was defined as tumor recurrence or progression of residual disease within the previous surgical field or detection of metastases on follow-up images. Overall survival (OS) was obtained from the Austrian death register in December 2016.

\section{Statistical analysis}

Statistical analysis was performed using SPSS ${ }^{\circledR}$ Statistics 22 (IBM Corp., Armonk, NY). Contingency tables were evaluated using Fisher's exact test. Group comparison was performed using the Mann-Whitney $U$ test. Progression-free survival (PFS) and OS was estimated with Kaplan-Meier analysis. Predictors for PFS or OS were identified using the log rank test. Differences were considered to be statistically significant at a two-sided $p$ value of $<0.05$.

\section{Results}

\section{Tumor resection}

Parenchymal infiltration was observed in $32.2 \%$ of patients and significantly associated with histological grading (4/4 CPC, 6/11 aCPP, 2/21 CPP; $p=0.001$ ).

GTR was achieved in $33(91.7 \%)$ patients. In all three cases with subtotal resection ( $2 \mathrm{aCPP}, 1 \mathrm{CPC}$ ), infiltration to medulla oblongata, thalamus, or caudal cranial nerves was present.

In one patient with disseminated CPC (patient no. 15), a solitary spinal metastasis was resected 10 days after first surgery. 


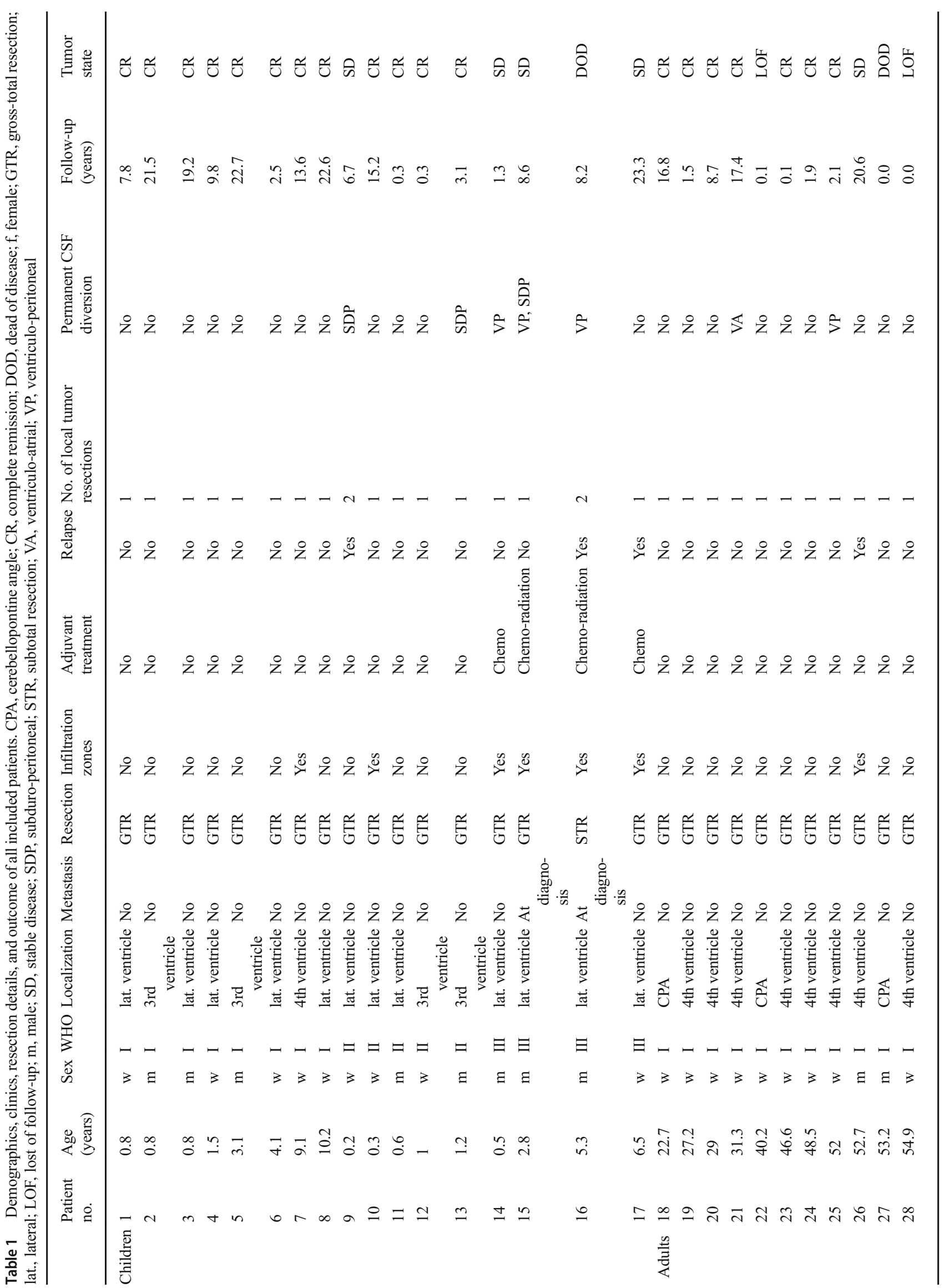




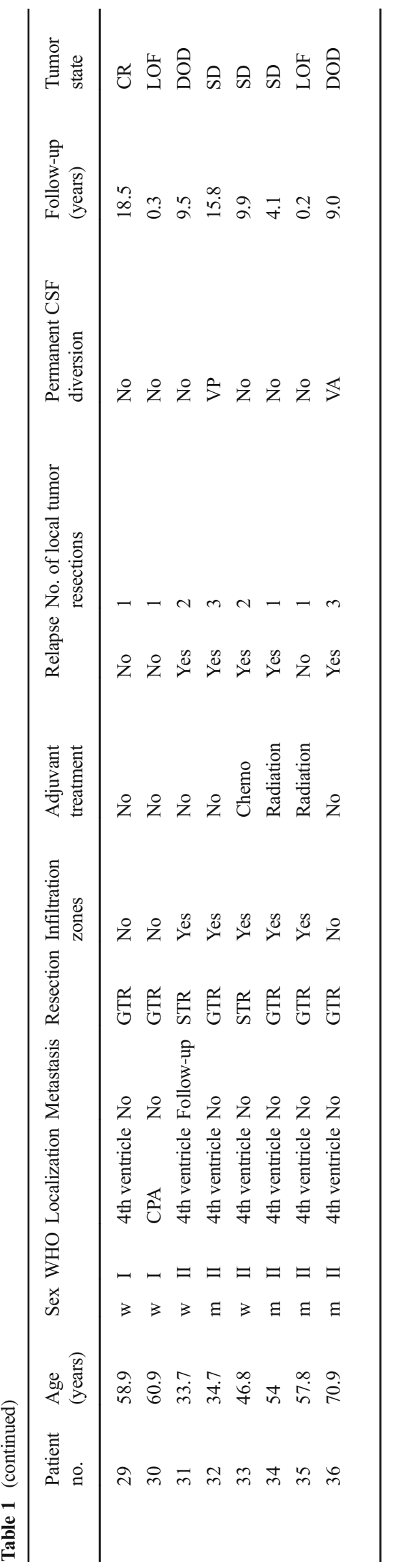

Table 2 Clinical presentation

\begin{tabular}{lll}
\hline & Children & Adults \\
\hline Increased ICP & $76.5 \%$ & $15.8 \%^{*}$ \\
Increased head circumference & $41.2 \%$ & $\mathrm{~N} / \mathrm{A}$ \\
Headache & $23.5 \%$ & $68.4 \%^{*}$ \\
Gait disturbance & $5.6 \%$ & $52.6 \% *$ \\
Vertigo & $7.1 \%$ & $36.8 \% *$ \\
Diplopia & $11.8 \%$ & $31.6 \%$ \\
Behavior & $35.3 \%$ & $5.3 \% *$ \\
Paresis & $17.6 \%$ & $10.5 \%$ \\
Incidential finding & $5.9 \%$ & $21.1 \%$ \\
\hline
\end{tabular}

*Significant differences between age groups $(p<0.05)$

\section{Intraoperative blood transfusion management}

Complete anesthesia protocols were available for 22 patients (61.1\%). Intraoperative blood transfusion was necessary for 5 out of 8 children with complete data (age, 0.5-5.3 years), including two CPC, one aCPP, and two CPP. The median volume of blood transfusion was $510 \mathrm{ml}$ (range, $150-1100 \mathrm{ml}$ amounting to $20-72 \%$ of estimated blood volume in these children). Tumor size was not significantly different in patients with blood transfusion (median size, $51.0 \mathrm{~mm}$ ) in comparison to patients without transfusion (median, $32.0 \mathrm{~mm}$; $p=0.14$ ).

\section{Short-term complications}

One adult with CPP succumbed from a sudden bleeding in the fourth ventricle resection cavity 3 days after surgery, resulting in a perioperative mortality of $2.7 \%$. Transient morbidity included electrolyte imbalance ( 2 patients), diplopia (1 patients), facial nerve palsy ( 2 patients), dysphagia ( 2 patients), ataxia (2 patients), and epidural hematoma requiring surgical evacuation (1 patient [48]).

Permanent morbidity at last follow-up was present in 2 adult patients including diplopia (2), unilateral hypacusis (1), and dysphagia (1).

One CPC child (no. 15) developed 1 year after primary surgery a refractory focal onset secondarily generalized epilepsy, but was seizure-free after temporo-parieto-occipital disconnection surgery.

Table 3 Tumor localization and surgical approach

\begin{tabular}{lllll}
\hline & Lat. ventricle & 3rd ventricle & 4th ventricle & CPA \\
\hline Suboccipital & - & - & 16 & 1 \\
Transcortical & 8 & 1 & - & - \\
Transcallosal & 4 & 2 & - & - \\
Supracerebellar & - & 1 & - & - \\
Retromastoidal & - & - & - & 3 \\
Total & 12 & 4 & 16 & 4 \\
\hline
\end{tabular}




\section{Impairment of CSF circulation}

External ventricular drainage (EVD) was placed in 6 children (35.3\%) and one adult (5.3\%) prior to resection due to acute intracranial hypertension. Delayed EVD placement after tumor resection was performed in 4 patients $(11.1 \%)$.

A ventricular-peritoneal (5 patients) or ventricular-atrial (2 patients) shunt was placed at a median interval of 27 days (range, $0-175$ days) after tumor resection. Permanent shunting was equally distributed between children and adults (17.6\% vs. $21.1 \% ; p=0.80)$, but was more frequent in CPC (75.0\%) than in aCPP $(18.2 \%)$ or CPP $(9.5 \% ; p=0.01)$.

Postoperative subdural hygroma was observed in 8 children (47.1\%), occurring after $4 / 6$ transcallosal (Fig. 2b) and after 4/9 transcortical approaches. Patients with postoperative hygroma had a significantly larger tumor ( $53 \mathrm{~mm}$ vs. $34 \mathrm{~mm} ; p=0.02$ ). A subduro-peritoneal shunt was placed in $3 / 8$ children due to progression of the hygroma, increased head circumferences (99.9 percentile), or significant cortical compression (Fig. 2c).

\section{Adjuvant therapy after initial surgery}

Adjuvant therapy was performed in $19.4 \%$ of patients.

Four children with CPC (6 months- 6.5 years) received chemotherapy. A combination of etoposide with either vincristine or ifosfamide and cisplatin or carboplatin was used. Additional radiotherapy was performed in $2 / 4$ children with CPC, both older than 3 years. One patient with spinal metastasis at diagnosis (patient no. 15) underwent cranio-spinal irradiation $(24 \mathrm{~Gy})$ with boosts to the primary tumor and metastates (25.2 Gy). The older child with a small spinal metastasis and tumor cells in the CSF (patient no. 16) underwent cranio-spinal irradiation with 35.2 Gy with a local cerebral boost of $20 \mathrm{~Gy}$ and spinal boost of $14 \mathrm{~Gy}$. None of the children with aCPP (0.2-1.2 years) received adjuvant treatment. A recurrent aCPP was totally resected after what had been assumed an initial GTR. On review, relapse was assumed to originate from a tiny residual at the Foramen of Monro.

Local radiotherapy (54 Gy) was administered to 2 adult patients with an aCPP and a highly increased MIB-Index after GTR (patient no. 34 and no. 35). One adult patient with an aCPP (no. 33) received adjuvant antiangiogenic therapy (thalidomide).

\section{Outcome}

Four patients were lost to clinical follow-up after GTR including $3 \mathrm{CPP}$ and one aCPP.

In the remaining 32 patients, median follow-up was 5.9 years (range, 0.1-20.8 years). Five-year OS for CPP was $95.2 \%$ and $100 \%$ for both aCPP and CPC. Ten-year OS for CPP was still 95.2\% and $66.7 \%$ for both aCPP and CPC (Fig. 1c, d).
Extent of resection $(p=0.01)$, tumor progression $(p=$ $0.04)$, and leptomeningeal metastasis $(p=0.002)$, but not histological grading $(p=0.27)$, were predictors for OS.

In total, four patients died (11.1\%): One patient with CPP died 3 days after primary surgery due to acute rebleeding (patient no. 27). One adult died due to a secondary metastasized aCPP (patient no. 31) and one child due to a metastasized CPC (patient no. 16). One patient with an aCPP died 9 years after first surgery due to ARDS and renal failure (patient no. 36).

Five-year PFS was $100 \%$ for CPP, $85.7 \%$ for aCPP, and $33.3 \%$ for CPC (Fig. 1a, b). Histology and extent of resection were statistically significant predictors of PFS $(p=0.01$ and $p=0.05$ respectively).

\section{Tumor recurrence}

Tumor recurrence was observed in nine patients $(25.0 \%)$, including one CPP, six aCPP, and two CPC. Median time to relapse was 4.0 years (range, $0.5-8.8$ years). Tumor progression was observed in all three patients with STR. Six of 33 (18.2\%) patients with GTR had a local relapse. Tumor recurrence was observed more frequently in patients with intraoperative evident brain infiltration (77.8\%) than in patients without infiltration $(22.2 \% ; p=0.001)$ and was significantly associated with histological grading $(p=0.004)$.

In 6/9 cases with tumor relapse, surgical resection was performed (Fig. 2d). Time to reoperation was independent of the initial extent of resection (4.2 years for STR vs. 3.9 years for GTR; $p=0.79$ ). Two patients with an aCPP required a third surgical intervention (patient no. 32 and no. 36).

One patient with a fourth ventricular aCPP (patient no. 31) underwent resection for local recurrence. This patient developed cranio-spinal dissemination and was treated with a combination of chemotherapy, gamma knife, and fractionated radiation as reported elsewhere [45].

Of the non-surgically managed relapse cases, one child with CPC (patient no. 17) was treated with intensive chemotherapy and gamma knife. In one adult with an asymptomatic recurrent CPP (patient no. 26), a wait-and-see strategy was chosen on patient's wish, and one patient with recurrent aCPP (patient no. 34) moved abroad.

One child with a posterior third ventricle CPP underwent a second surgery years later because of a new contrastenhancing lesion at the primary tumor site. Scar tissue only with no evidence of tumor was found at resection.

Leptomeningeal seeding was present in $8.3 \%$ of patients (one aCPP, two CPC). Two CPC cases had spinal metastases already at diagnosis (patient no. 15 and no. 16). In the aCPP patient (patient no. 31), a spinal metastasis was resected 4.6 years after primary surgery, confirming the initial histology of an aCPP. 
Fig. 1 Kaplan-Meier plot displaying progression-free survival $(\mathbf{a}, \mathbf{b})$ and overall survival $(\mathbf{c}, \mathbf{d})$ in relation to histological tumor grade and extent of resection. aCPP, atypical choroid plexus papilloma; CPC, choroid plexus carcinoma; CPP, choroid plexus papilloma; GTR, gross-total resection; STR, subtotal resection a

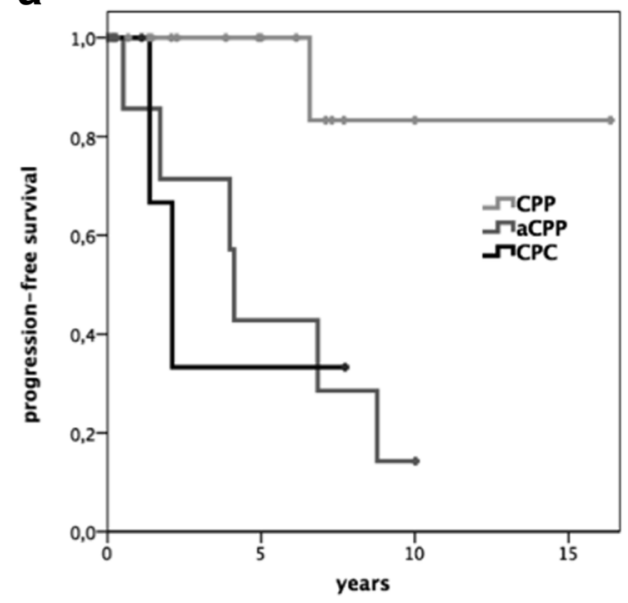

C

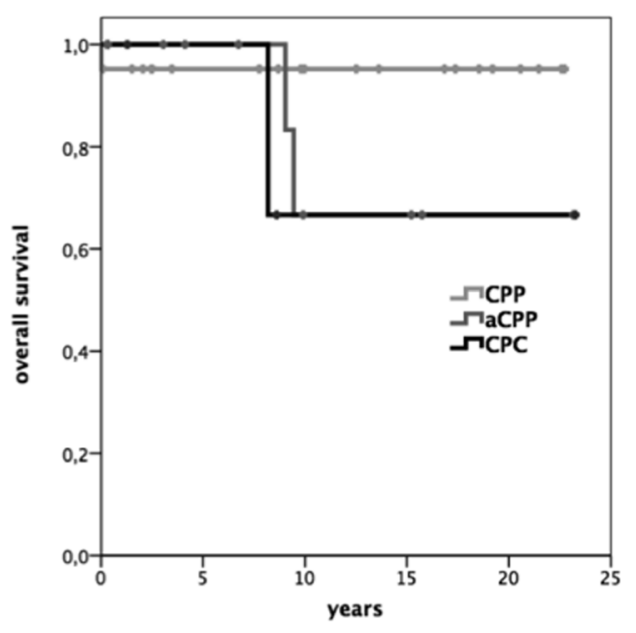

b

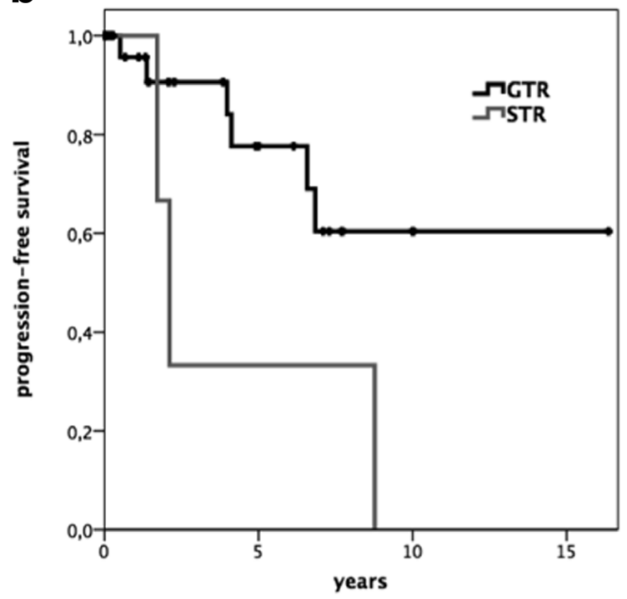

d

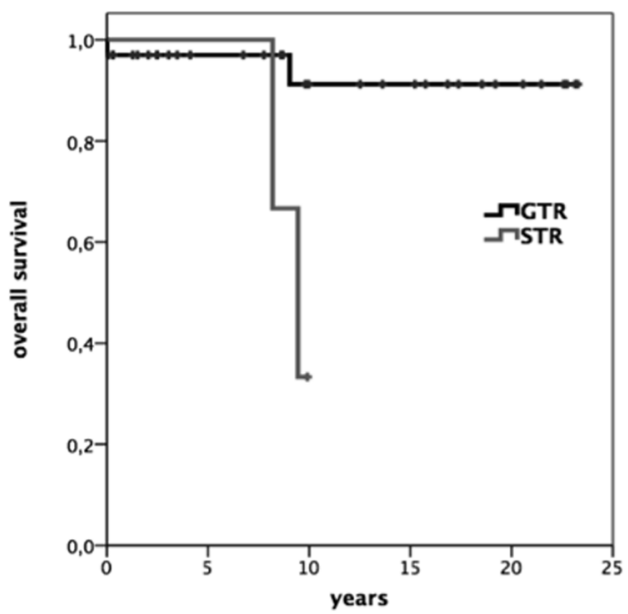

\section{Differences in children and adults}

Differences in symptoms at diagnosis between children and adults are shown in Table 2. Histological tumor grading was higher in children than in adults. CPP was observed more frequently in adults $(68.4 \%)$ than in children $(47.1 \%)$, whereas frequency of aCPP was equal in both age groups (Fig. 3). CPC were diagnosed only in children and tend to occur more frequently in male than in female patients ( $21.4 \%$ vs. $4.6 \% ; p=0.1)$.

In adults, tumors were situated exclusively infratentorially, whereas in children, tumors were located supratentorially, except for one patient, where the tumor was located within the fourth ventricle.

Intraoperatively evident parenchymal tumor infiltration and extent of resection were equally distributed between children and adults. However, blood transfusion was necessary only in children.

Overall placement of EVD was more frequent in children $(41.2 \%)$ than in adults $(41.2 \%)$, but did not reach statistical significance $(p=0.19)$. However, EVD placement in children was performed mostly prior to tumor resection $(85.7 \%)$, whereas in adults mainly after tumor resection $(75.0 \% ; p=$ 0.04). Permanent ventricular shunting was equally distributed between children and adults (17.6\% and $21.1 \%$, respectively; $p=0.80$ ), but subduro-peritoneal shunting was performed only in children (17.7\%).

Although, histological grading was higher in children, PFS and OS were equal in children and adults $(p=0.37$ and $p=$ 0.43, respectively; Fig. 4).

\section{Discussion}

In our long-term cohort of a mixed pediatric and adult population, we outlined the age-specific differences for CPTs and delineated the surgically non-negligible postoperative disturbances of CSF circulation in this disease.

Although CPTs revealed higher histological grading in the pediatric population, PFS and OS were equal in children and adults. In children, the CPT was located nearly exclusively 

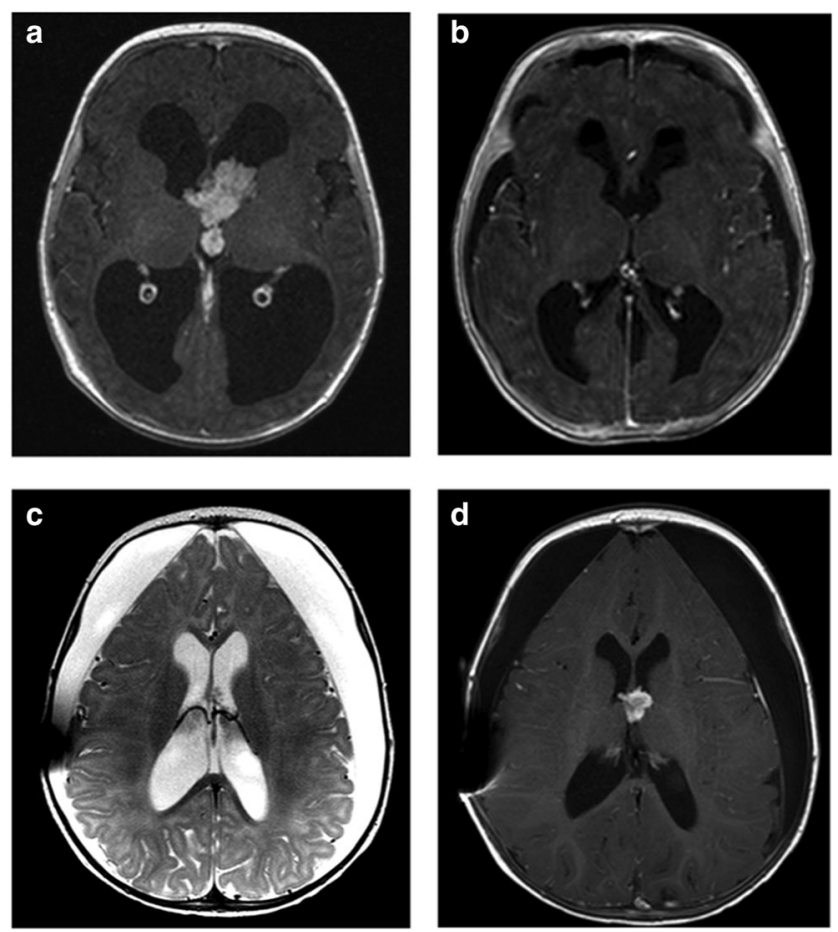

Fig. 2 Illustrative case no. 9. A 2-month-old girl presented with increased head circumference ( $>97$ th percentile) and a contrast-enhanced intraventricular lesion at the Foramen of Monro (a). Using a transcallosal approach the tumor was totally resected (b) and histopathology diagnosed an atypical choroid plexus papilloma. Preoperative hydrocephalus resolved, but a subduro-peritoneal shunt was necessary due to postoperative persistent subdural hygroma (c). Followup MRI scans revealed tumor recurrence 7 months after primary surgery (d), which was resected via a transcallosal approach. Long-term followup (6.7 years) showed complete remission and excellent neurological outcome

supratentorial and caused mostly symptoms of intracranial hypertension. One out of five patients - mostly children - required even an EVD ad admission. Our standardized institutional

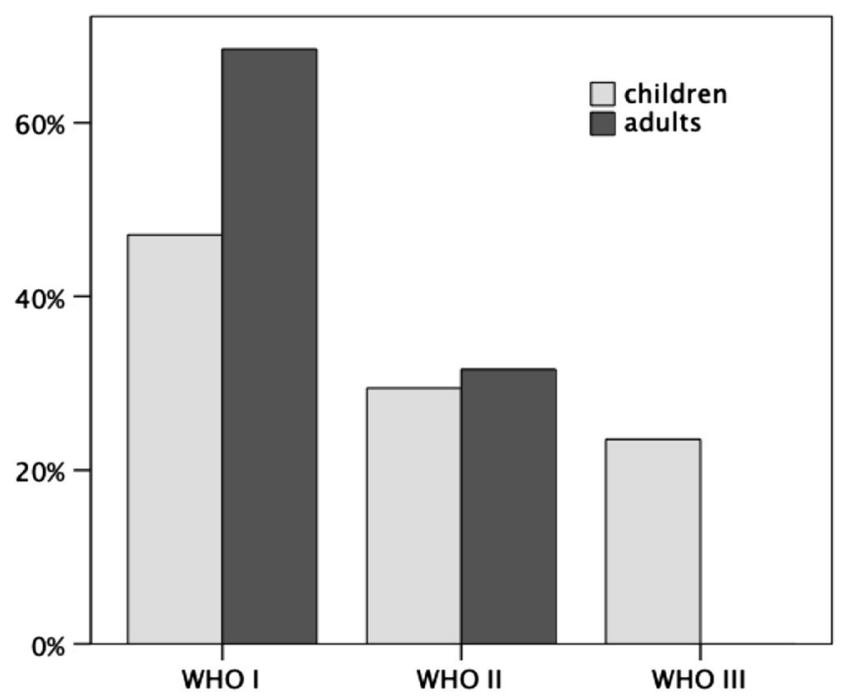

Fig. 3 Percentage of histological grading in children and adults protocol is temporary CSF drainage, if required in the acute setting and reassessment of permanent shunt implantation after tumor removal. As less than half of the patients with an initial EVD required permanent drainage, the shunting rate of $19.4 \%$ was lower in our patients than reported in other series $[22,25,30$, 35]. Our rationale of initial temporary CSF drainage until tumor removal is that the hydrocephalus is mostly caused by CSF flow obstruction by the tumor. Additional potential factors in the development of hydrocephalus are CSF overproduction by the tumor itself [33] and the increase in the CSF pulse wave $[6,8,11]$. Although this tumor entity is usually given as an example of hydrocephalus related to CSF overproduction, hydrocephalus may persist after total resection. Some cases of flow obstruction can be attributed to formation of obstructive scar tissue as observed in one of our patients. However, in most cases, microbleedings or necrosis of the tumor cause impairment of CSF absorption $[8,13]$, which may explain the higher incidence of permanent ventricular diversion in CPC patients.

Permanent ventricular shunting was equal in both age groups, but subduro-peritoneal shunting was necessary only in children. Subdural hygroma is a common postoperative complication especially in children after transcortical and transcallosal approaches. It is caused by surgically generated ventriculo-subdural fistula on the background of the collapsed hemisphere after tumor removal $[7,8,22,24]$. The association between tumor size and incidence of subdural hygroma may be explained by the higher incidence of hydrocephalus in larger tumors, thereby creating a cranio-cerebral disproportion with consecutive hygroma after tumor resection.

Neurological outcome can be affected significantly by perioperative morbidity [7, 42, 48] and tumor recurrence [21]. The high tumor vascularization and small circulating blood volume in infants may lead to life-threatening intraoperative bleeding with a perioperative mortality up to $12.5 \%$ [13]. Some authors suggest pre-operative embolization of feeding arteries to reduce intraoperative blood loss and improve the chance of GTR [18, 46]. However, despite high-volume experience with endovascular techniques at our center over the whole study period $[4,12,19]$, we do not use embolization as the complication rate, including infarction or hemorrhage, is not negligible [18]. Therefore, precise hemostasis during resection is even more crucial to avoid fatal complications especially in children.

GTR is the most important prognostic factor in CPTs [2, $15,39,47]$. We could show that GTR is essential for long OS and PFS, but detection of brain invasion at surgery is as well a strong predictor for tumor recurrence. The infiltrative growth of aCPP resembles the appearance of CPC, resulting in poor OS and PFS as well in aCPP cases. Patients with CPP can usually be cured by surgery alone $[23,35]$ and GTR in CPC patients has a significant impact on survival $[5,9,15,27,34]$. In our cohort, GTR was strongly associated with higher survival rates and a decreased risk of tumor recurrence. It has been reported that tumor recurrence had only an impact on 
Fig. 4 Kaplan-Meier plot displaying progression-free survival (a) and overall survival (b) for children and adults a

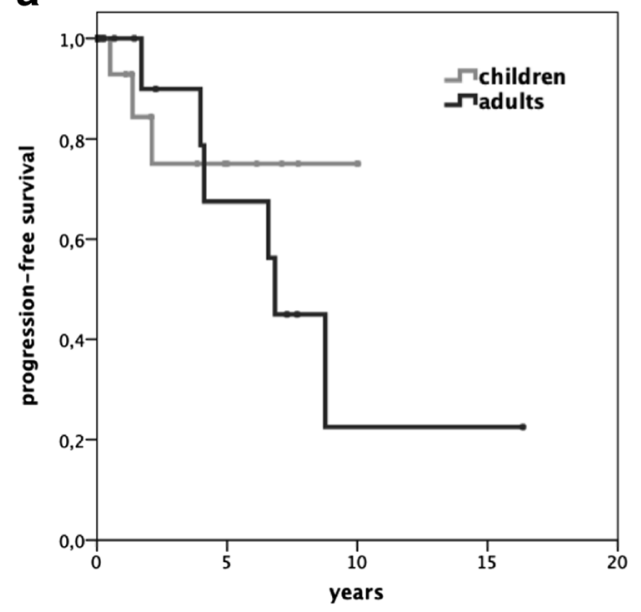

b

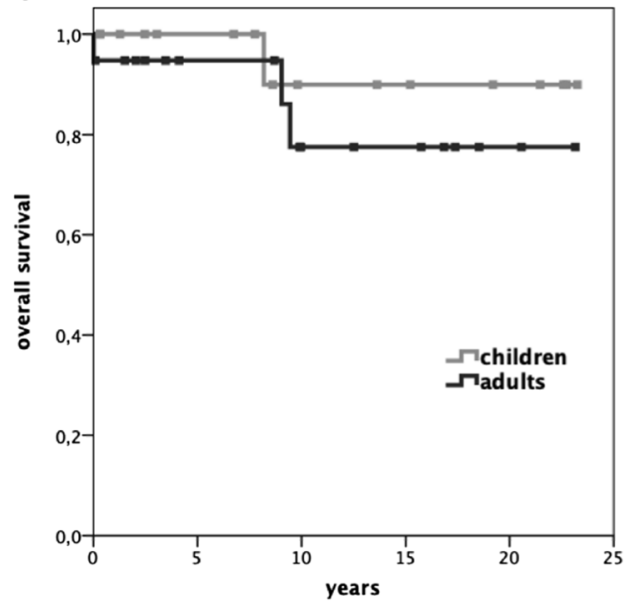

survival in patients with CPC and not in patients with CPP [47]. In our cohort, tumor recurrence was in fact a negative predictor of OS, but there was no association of OS with tumor entity. We observed brain infiltration at surgery more frequently in patients with later tumor recurrence. Levy et al. also described local parenchymal invasion in some CPP patients, but without noting an impact on tumor recurrence [26]. According to our findings, we suggest to assign adult patients with intraoperative evident parenchymal invasion to a highrisk group for relapse. As tumor recurrence was observed up to 8 years after primary surgery, neuroradiological follow-up should be performed on a long-term basis.

Whereas metastatic disease in CPC is common [9, 47], dissemination of CPP or aCPP is very rare and has been reported in only a few cases so far $[1,32,49]$. We observed cranio-spinal leptomeningeal dissemination at recurrence in one adult fourth ventricular aCPP patient (9\% of aCPP) with only STR at initial surgery. Therefore, MRI of the whole neuroaxis must be considered at recurrence of aCPPs and CPC. Although systemic metastases have been reported [47], we did not observe such an event in our patients.

In CPC, neoadjuvant chemotherapy has been proposed [38] but has not been used in our series. While various drug regimens are recommended after resection [2, 37], the role of radiotherapy with regard to timing, dose, and extent of the field remains to be determined [16, 29, 40]. Most series suggest a survival benefit of radiation in CPC patients [27, 47], excluding patients with germline mutation of p53 [3]. We performed adjuvant radiation of the neuroaxis in all patients with CPC older than 3 years of age, except one, who was not irradiated at primary therapy but received gamma knife treatment for a local tumor recurrence. The significantly higher 5-year OS of CPC patients (100\%) than their 5-year PFS (33.3\%) may be explained by the efficacy of the adjuvant therapy as reported elsewhere. [39].

Management of subtotally resected and recurrent CPPs and aCPPs remains controversial. Both of our subtotally resected $\mathrm{aCPP}$ of the fourth ventricle recurred. Chemotherapy is used in experimental settings only, and mostly limited to tumor recurrence, as already reported in one of our patients with a metastatic aCPP [45]. Local radiotherapy has been proposed in incompletely resected aCPPs [49]. In our series, both adults with fourth ventricular aCPP and postoperative local radiotherapy had had an initial GTR.

In most of our CPP and aCPP patients (5/7), resection was performed for local recurrence. Chemotherapy has also been reported as a viable treatment option $[28,45]$. In case of metastatic recurrence, our treatment regimen was chemotherapy and/or radiation, which was preceded by resection dependent on extent of disease.

Histological grade was reported as the strongest predictor of OS [9, 47]. Five-year OS of $95.2 \%$ for CPP and $100 \%$ for both aCPP and CPC are comparatively good as observed in other series [9, 23, 27, 39, 47, 50]. One of the five children aged less than 14 months with a diagnosis of aCPP and surgery only recurred compared with a recurrence rate of $83 \%$ in our adult patients, which is in line with data of the SIOP (the International Society of Pediatric Oncology) registry [43].

aCPP can be diagnosed by histological patterns alone. However, molecular patterns beyond histological grading may account for differences in clinical outcome [31, 36, 41, 49]. It has been shown that genetic and epigenetic patterns clearly distinguish CPC from CPP and aCPP [31]. The molecular similarity of aCPP and CPP may explain the rare progression of some CPP to aCPP $(<2 \%)[2,10,21]$. Methylation profiling could define risk subgroups, independent of histological grading [44]. This may explain the rare progression of grade I/II tumors to $\mathrm{CPC}$ [21] and is in line with data on pediatric aCPP [43]. Proliferation marker (Ki-67/MIB-1) and tumor suppressor proteins (p53) have been shown to gradually increase from CPP to aCPP and CPC with a high correlation to clinical outcome [49]. P53 mutations are found in over $50 \%$ of CPC patients [41], which are linked to increased tumor aggressiveness and decreased chemo- and radiosensitivity [14]. Not only the number of mutated copies but also structural variations of p53 are associated with 
worse PFS and OS [31, 41, 44]. Furthermore, age-related chromosomal alterations correlate to overall survival in CPC patients [36]. These heterogeneous molecular patterns reveal new highrisk groups beyond histological grading and may explain differences in clinical outcome. In future, the implementation of molecular data may improve therapy allocation and prediction of clinical outcome.

\section{Conclusion}

GTR is the most important predictor of OS regardless of histological grading. The question of adjuvant therapy is still in a process of being defined, but molecular patterns will have to be included in the future to provide adequate individual treatment in a multidisciplinary approach. The intraventricular location, tumor vascularization, and impaired CSF circulation have to be considered in the surgical approach in an age-related context to reduce perioperative morbidity. Especially, the sequelae of CSF diversion must not be underestimated in the pediatric population. Long-term follow-up is necessary in all patients as metastases and relapse may occur in all subtypes.

Funding Information Open access funding provided by Medical University of Vienna.

\section{Compliance with ethical standards}

Conflict of interest The authors declare that they have no conflict of interest.

Ethical approval All procedures performed in studies involving human participants were in accordance with the ethical standards of the institutional and/or national research committee and with the 1964 Helsinki declaration and its later amendments or comparable ethical standards.

Informed consent The study protocol was approved by the local ethics committee (EK 2005/2015). For this type of study, formal consent is not required.

Open Access This article is distributed under the terms of the Creative Commons Attribution 4.0 International License (http:// creativecommons.org/licenses/by/4.0/), which permits unrestricted use, distribution, and reproduction in any medium, provided you give appropriate credit to the original author(s) and the source, provide a link to the Creative Commons license, and indicate if changes were made.

Publisher's note Springer Nature remains neutral with regard to jurisdictional claims in published maps and institutional affiliations.

\section{References}

1. Abdulkader MM, Mansour NH, Van Gompel JJ, Bosh GA, Dropcho EJ, Bonnin JM, Cohen-Gadol AA (2016) Disseminated choroid plexus papillomas in adults: a case series and review of the literature. J Clin Neurosci 32:148-154. https://doi.org/10.1016/j.jocn.2016.04.002

2. Bahar M, Hashem H, Tekautz T, Worley S, Tang A, de Blank P, Wolff J (2017) Choroid plexus tumors in adult and pediatric populations: the
Cleveland Clinic and University Hospitals experience. J Neuro-Oncol 132:427-432. https://doi.org/10.1007/s11060-017-2384-1

3. Bahar M, Kordes U, Tekautz T, Wolff J (2015) Radiation therapy for choroid plexus carcinoma patients with Li-Fraumeni syndrome: advantageous or detrimental? Anticancer Res 35:3013-3017

4. Bavinzski G, Killer M, Gruber A, Reinprecht A, Gross CE, Richling B (1999) Treatment of basilar artery bifurcation aneurysms by using Guglielmi detachable coils: a 6-year experience. J Neurosurg 90:843852. https://doi.org/10.3171/jns.1999.90.5.0843

5. Berger C, Thiesse P, Lellouch-Tubiana A, Kalifa C, Pierre-Kahn A, Bouffet E (1998) Choroid plexus carcinomas in childhood: clinical features and prognostic factors. Neurosurgery 42:470-475

6. Bering EA (1962) Circulation of the cerebrospinal fluid. Demonstration of the choroid plexuses as the generator of the force for flow of fluid and ventricular enlargement. J Neurosurg 19:405413. https://doi.org/10.3171/jns.1962.19.5.0405

7. Bettegowda C, Adogwa O, Mehta V, Chaichana KL, Weingart J, Carson BS, Jallo GI, Ahn ES (2012) Treatment of choroid plexus tumors: a 20-year single institutional experience. J Neurosurg Pediatr 10:398-405. https://doi.org/10.3171/2012.8.PEDS12132

8. Boyd MC, Steinbok P (1987) Choroid plexus tumors: problems in diagnosis and management. J Neurosurg 66:800-805. https://doi. org/10.3171/jns.1987.66.6.0800

9. Cannon DM, Mohindra P, Gondi V, Kruser TJ, Kozak KR (2015) Choroid plexus tumor epidemiology and outcomes: implications for surgical and radiotherapeutic management. J Neuro-Oncol 121:151-157. https://doi.org/10.1007/s11060-014-1616-x

10. Chow E, Jenkins JJ, Burger PC, Reardon DA, Langston JW, Sanford RA, Heideman RL, Kun LE, Merchant TE (1999) Malignant evolution of choroid plexus papilloma. Pediatr Neurosurg 31:127-130

11. Di Rocco C, Pettorossi VE, Caldarelli M, Mancinelli R, Velardi F (1977) Experimental hydrocephalus following mechanical increment of intraventricular pulse pressure. Experientia 33:1470-1472

12. Dorfer C, Czech T, Bavinzski G, Kitz K, Mert A, Knosp E, Gruber A (2010) Multimodality treatment of cerebral AVMs in children: a single-centre 20 years experience. Childs Nerv Syst 26:681-687. https://doi.org/10.1007/s00381-009-1039-8

13. Due-Tønnessen B, Helseth E, Skullerud K, Lundar T (2001) Choroid plexus tumors in children and young adults: report of 16 consecutive cases. Childs Nerv Syst 17:252-256

14. El-Deiry WS (2003) The role of p53 in chemosensitivity and radiosensitivity. Oncogene 22:7486-7495. https://doi.org/10.1038/sj.onc.1206949

15. Ellenbogen RG, Winston KR, Kupsky WJ (1989) Tumors of the choroid plexus in children. Neurosurgery 25:327-335

16. Fitzpatrick LK, Aronson LJ, Cohen KJ (2002) Is there a requirement for adjuvant therapy for choroid plexus carcinoma that has been completely resected? J Neuro-Oncol 57:123-126

17. Gupta N (2003) Choroid plexus tumors in children. Neurosurg Clin N Am 14:621-631

18. Haliasos N, Brew S, Robertson F, Hayward R, Thompson D, Chakraborty A (2013) Preoperative embolisation of choroid plexus tumours in children: part I-does the reduction of perioperative blood loss affect the safety of subsequent surgery? Childs Nerv Syst 29: 65-70. https://doi.org/10.1007/s00381-012-1912-8

19. Hosmann A, El-Garci A, Gatterbauer B, Bavinzski G, Knosp E, Gruber A (2018) Multimodality management of vein of Galen malformations-an institutional experience. World Neurosurg 112: e837-e847. https://doi.org/10.1016/j.wneu.2018.01.172

20. Jeibmann A, Hasselblatt M, Gerss J, Wrede B, Egensperger R, Beschorner R, Hans VH, Rickert CH, Wolff JE, Paulus W (2006) Prognostic implications of atypical histologic features in choroid plexus papilloma. J Neuropathol Exp Neurol 65:1069-1073. https://doi.org/10.1097/01.jnen.0000240464.26005.90

21. Jeibmann A, Wrede B, Peters O, Wolff JE, Paulus W, Hasselblatt M (2007) Malignant progression in choroid plexus papillomas. J Neurosurg 107:199-202. https://doi.org/10.3171/PED-07/09/199 
22. Koh EJ, Wang KC, Phi JH, Lee JY, Choi JW, Park SH, Park KD, Kim IH, Cho BK, Kim SK (2014) Clinical outcome of pediatric choroid plexus tumors: retrospective analysis from a single institute. Childs Nerv Syst 30:217-225. https://doi.org/10.1007/s00381-013-2223-4

23. Krishnan S, Brown PD, Scheithauer BW, Ebersold MJ, Hammack JE, Buckner JC (2004) Choroid plexus papillomas: a single institutional experience. J Neuro-Oncol 68:49-55

24. Kumar R, Singh S (2005) Childhood choroid plexus papillomas: operative complications. Childs Nerv Syst 21:138-143. https://doi. org/10.1007/s00381-004-0993-4

25. Lena G, Genitori L, Molina J, Legatte JR, Choux M (1990) Choroid plexus tumours in children. Review of 24 cases. Acta Neurochir 106:68-72

26. Levy ML, Goldfarb A, Hyder DJ, Gonzales-Gomez I, Nelson M, Gilles FH, McComb JG (2001) Choroid plexus tumors in children: significance of stromal invasion. Neurosurgery 48:303-309

27. Mallick S, Benson R, Melgandi W, Rath GK (2017) Effect of surgery, adjuvant therapy, and other prognostic factors on choroid plexus carcinoma: a systematic review and individual patient data analysis. Int J Radiat Oncol Biol Phys. https://doi.org/10.1016/j. ijrobp.2017.08.012

28. Maria BL, Graham ML, Strauss LC, Wharam MD (1985) Response of a recurrent choroid plexus tumor to combination chemotherapy. $\mathrm{J}$ Neuro-Oncol 3:259-262

29. Mazloom A, Wolff JE, Paulino AC (2010) The impact of radiotherapy fields in the treatment of patients with choroid plexus carcinoma. Int J Radiat Oncol Biol Phys 78:79-84. https://doi.org/10.1016/ j.ijrobp.2009.07.1701

30. McEvoy AW, Harding BN, Phipps KP, Ellison DW, Elsmore AJ, Thompson D, Harkness W, Hayward RD (2000) Management of choroid plexus tumours in children: 20 years experience at a single neurosurgical centre. Pediatr Neurosurg 32:192-199

31. Merino DM, Shlien A, Villani A, Pienkowska M, Mack S, Ramaswamy V, Shih D, Tatevossian R, Novokmet A, Choufani S, Dvir R, Ben-Arush M, Harris BT, Hwang EI, Lulla R, Pfister SM, Achatz MI, Jabado N, Finlay JL, Weksberg R, Bouffet E, Hawkins C, Taylor MD, Tabori U, Ellison DW, Gilbertson RJ, Malkin D (2015) Molecular characterization of choroid plexus tumors reveals novel clinically relevant subgroups. Clin Cancer Res 21:184-192. https://doi.org/10.1158/1078-0432.CCR-14-1324

32. Morshed RA, Lau D, Sun PP, Ostling LR (2017) Spinal drop metastasis from a benign fourth ventricular choroid plexus papilloma in a pediatric patient: case report. J Neurosurg Pediatr:1-9. https:// doi.org/10.3171/2017.5.PEDS17130

33. Nimjee SM, Powers CJ, McLendon RE, Grant GA, Fuchs HE (2010) Single-stage bilateral choroid plexectomy for choroid plexus papilloma in a patient presenting with high cerebrospinal fluid output. J Neurosurg Pediatr 5:342-345. https://doi.org/10.3171/2009.10.PEDS08454

34. Packer RJ, Perilongo G, Johnson D, Sutton LN, Vezina G, Zimmerman RA, Ryan J, Reaman G, Schut L (1992) Choroid plexus carcinoma of childhood. Cancer 69:580-585

35. Pencalet P, Sainte-Rose C, Lellouch-Tubiana A, Kalifa C, Brunelle F, Sgouros S, Meyer P, Cinalli G, Zerah M, Pierre-Kahn A, Renier D (1998) Papillomas and carcinomas of the choroid plexus in children. J Neurosurg 88:521-528. https://doi.org/10.3171/jns.1998.88.3.0521

36. Ruland V, Hartung S, Kordes U, Wolff JE, Paulus W, Hasselblatt M (2014) Choroid plexus carcinomas are characterized by complex chromosomal alterations related to patient age and prognosis. Genes Chromosomes Cancer 53:373-380. https://doi.org/10.1002/gcc.22148

37. Rytting ME (2017) CPT-SIOP-2009: Intercontinental multidisciplinary registry and treatment optimization study for patients with choroid plexus tumors. https://clinicaltrials.gov/ct2/show/NCT00500890. Accessed 3 sept 2018

38. Schneider C, Kamaly-Asl I, Ramaswamy V, Lafay-Cousin L, Kulkarni AV, Rutka JT, Remke M, Coluccia D, Tabori U, Hawkins C, Bouffet E, Taylor MD (2015) Neoadjuvant chemotherapy reduces blood loss during the resection of pediatric choroid plexus carcinomas. J Neurosurg Pediatr 16:126-133. https://doi.org/10.3171/2014.12.PEDS14372

39. Siegfried A, Morin S, Munzer C, Delisle MB, Gambart M, Puget S, Maurage CA, Miquel C, Dufour C, Leblond P, André N, Branger DF, Kanold J, Kemeny JL, Icher C, Vital A, Coste EU, Bertozzi AI (2017) A French retrospective study on clinical outcome in 102 choroid plexus tumors in children. J Neuro-Oncol 135:151-160. https://doi.org/10.1007/s11060-017-2561-2

40. Sun MZ, Ivan ME, Oh MC, Delance AR, Clark AJ, Safaee M, Oh T, Kaur G, Molinaro A, Gupta N, Parsa AT (2014) Effects of adjuvant chemotherapy and radiation on overall survival in children with choroid plexus carcinoma. J Neuro-Oncol 120:353-360. https://doi.org/10.1007/s11060-014-1559-2

41. Tabori U, Shlien A, Baskin B, Levitt S, Ray P, Alon N, Hawkins C, Bouffet E, Pienkowska M, Lafay-Cousin L, Gozali A, Zhukova N, Shane L, Gonzalez I, Finlay J, Malkin D (2010) TP53 alterations determine clinical subgroups and survival of patients with choroid plexus tumors. J Clin Oncol 28:1995-2001. https://doi.org/10. 1200/JCO.2009.26.8169

42. Tacconi L, Delfini R, Cantore G (1996) Choroid plexus papillomas: consideration of a surgical series of 33 cases. Acta Neurochir 138: 802-810

43. Thomas C, Ruland V, Kordes U, Hartung S, Capper D, Pietsch T, Gerß J, Wolff JE, Paulus W, Hasselblatt M (2015) Pediatric atypical choroid plexus papilloma reconsidered: increased mitotic activity is prognostic only in older children. Acta Neuropathol 129:925-927. https://doi.org/10.1007/s00401-015-1434-Z

44. Thomas C, Sill M, Ruland V, Witten A, Hartung S, Kordes U, Jeibmann A, Beschorner R, Keyvani K, Bergmann M, Mittelbronn M, Pietsch T, Felsberg J, Monoranu CM, Varlet P, Hauser P, Olar A, Grundy RG, Wolff JE, Korshunov A, Jones DT, Bewerunge-Hudler M, Hovestadt V, von Deimling A, Pfister SM, Paulus W, Capper D, Hasselblatt M (2016) Methylation profiling of choroid plexus tumors reveals 3 clinically distinct subgroups. Neuro-Oncology 18:790-796. https://doi.org/10.1093/neuonc/nov322

45. Valencak J, Dietrich W, Raderer M, Dieckmann K, Prayer D, Hainfellner JA, Marosi C (2000) Evidence of therapeutic efficacy of CCNU in recurrent choroid plexus papilloma. J Neuro-Oncol 49: 263-268

46. Wind JJ, Bell RS, Bank WO, Myseros JS (2010) Treatment of third ventricular choroid plexus papilloma in an infant with embolization alone. J Neurosurg Pediatr 6:579-582. https://doi.org/10.3171/ 2010.9.PEDS1039

47. Wolff JE, Sajedi M, Brant R, Coppes MJ, Egeler RM (2002) Choroid plexus tumours. Br J Cancer 87:1086-1091. https://doi. org/10.1038/sj.bjc.6600609

48. Wolfsberger S, Gruber A, Czech T (2004) Multiple supratentorial epidural haematomas after posterior fossa surgery. Neurosurg Rev 27:128-132. https://doi.org/10.1007/s10143-003-0315-4

49. Wrede B, Hasselblatt M, Peters O, Thall PF, Kutluk T, Moghrabi A, Mahajan A, Rutkowski S, Diez B, Wang X, Pietsch T, Kortmann RD, Paulus W, Jeibmann A, Wolff JE (2009) Atypical choroid plexus papilloma: clinical experience in the CPT-SIOP-2000 study. J NeuroOncol 95:383-392. https://doi.org/10.1007/s11060-009-9936-y

50. Zaky W, Dhall G, Khatua S, Brown RJ, Ginn KF, Gardner SL, Yildiz VO, Yankelevich M, Finlay JL (2015) Choroid plexus carcinoma in children: the Head Start experience. Pediatr Blood Cancer 62:784-789. https://doi.org/10.1002/pbc.25436

Comments Well-written work that may serve as recommendation for surgeons on how to treat this relatively rare entity. Its worth to read.

Jane Skjoth-Rasmussen

Copenhagen, Denmark 